\title{
Biossegurança e Odontologia: crenças $e$ atitudes de graduandos sobre o controle da infecção cruzada'
}

\section{Biosecurity and Dentistry: beliefs and attitudes among dental students regarding infection control}

\author{
Camila Pinelli \\ Professora Doutora. Docente das Disciplinas de Orientação Profis- \\ sional e Ergonomia em Odontologia da Faculdade de Odontologia \\ de Araraquara (Unesp). \\ Endereço: Faculdade de Odontologia de Araraquara - UNESP, \\ Departamento de Odontologia Social, Rua Humaitá, 1680, CXP 331, \\ CEP 1480I-903, Centro, Araraquara, SP, Brasil. \\ E-mail: cpinelliðfoar.unesp.br

\section{Patrícia Petromili Nordi Sasso Garcia} \\ Professora Doutora. Docente das Disciplinas de Orientação Profis- \\ sional e Ergonomia em Odontologia da Faculdade de Odontologia \\ de Araraquara (Unesp). \\ Endereço: Faculdade de Odontologia de Araraquara - UNESP, \\ Departamento de Odontologia Social, Rua Humaitá, 1680, CXP 331, \\ CEP 14801-903, Centro, Araraquara, SP, Brasil. \\ E-mail: psgarcia®foar.unesp.br

\section{Juliana Álvares Duarte Bonini Campos} \\ Professora Doutora. Docente da Disciplina de Bioestatística e \\ Metodologia Científica da Faculdade de Odontologia de Arara- \\ quara (Unesp). \\ Endereço: Faculdade de Odontologia de Araraquara - UNESP, \\ Departamento de Odontologia Social, Rua Humaitá, 1680, CXP 331, \\ CEP 1480I-903, Centro, Araraquara, SP, Brasil. \\ E-mail: jucamposळfoar.unesp.br
}

\section{Edivani Aparecida Vicente Dotta}

Professora Doutora. Docente da Disciplina de Informática em Odontologia da Faculdade de Odontologia de Araraquara (Unesp).

Endereço: Faculdade de Odontologia de Araraquara - UNESP, Departamento de Odontologia Social, Rua Humaitá, 1680, CXP 331, CEP 14801-903, Centro, Araraquara, SP, Brasil.

E-mail: edivaniळfoar.unesp.br

\section{Ariele Patrícia Rabello}

Cirurgiã-dentista. Bolsista de Treinamento Técnico pela Fapesp. Endereço: Faculdade de Odontologia de Araraquara - UNESP, Departamento de Odontologia Social, Rua Humaitá, 1680, CXP 331, CEP 14801-903, Centro, Araraquara, SP, Brasil.

E-mail:arieleprabello®foar.unesp.br

I Financiamento Fapesp, processos nㅡㅇ 07/04595-8 e ํㅜ 08/10737-2.

\section{Resumo}

Este estudo teve o objetivo de investigar as percepções de graduandos de Odontologia sobre a fidelidade às diretrizes de biossegurança e acerca do preservar-se. Nove questões abertas, que abordaram aspectos de interesse para o tema, foram aplicadas em entrevista com 14 acadêmicos, que realizavam atendimento odontológico de pacientes da Faculdade de Odontologia de Araraquara da Unesp. Utilizouse a metodologia de pesquisa qualitativa e a estratégia metodológica para análise das entrevistas foi a Discurso do Sujeito Coletivo (DSC). Três figuras metodológicas foram obtidas, sendo ideias-centrais, expressões-chave e o DSC propriamente dito. A análise dos discursos permitiu avaliar a fala natural da coletividade. Verificou-se a adesão dos entrevistados aos protocolos de biossegurança, embora houvesse a queixa de que, na rotina diária, as precauções fossem negligenciadas por não serem muito práticas. Entre as medidas de proteção individual e coletiva, rotineiramente utilizadas, foram apontados o uso de Equipamento de Proteção Individual (EPI) e as barreiras protetoras, bem como as atividades de desinfecção e esterilização. O risco de contágio foi visto por alguns com pavor e por outros com total indiferença porque acreditavam ser algo do qual é possível de se ter controle por meio da adesão às precauções padrão. Entre as doenças de maior preocupação, a aids e as hepatites B e C foram as mais temidas. Diante do discurso obtido, salientase a necessidade de se aperfeiçoar as estratégias educacionais, com intuito de motivar a fiel adesão às normas de biossegurança, essenciais no trato de pacientes odontológicos.

Palavras-chave: Biossegurança; Estudantes de Odontologia; Fidelidade a Diretrizes; Pesquisa Qualitativa. 


\section{Abstract}

The aim of the present study was to investigate dental students' perceptions in relation to adherence to Biosecurity guidelines and self-preservation. Nine open questions that approached aspects regarding the issue were asked in interview to 14 dental students who assisted dental patients at the Araraquara School of Dentistry - UNESP. The qualitative methodology was used and the Collective Subject Discourse (CSD) was the methodological strategy for interview analysis. Three methodological figures were obtained: central ideas, key expressions and the CSD itself. The natural collective discourse was obtained. Adherence to Biosecurity protocols was reported, although the students complained that, in the daily routine, the precautions were neglected because they are not practical. Among collective and individual precautions were the use of Personal Protective Equipment (PPE), protective barriers, and disinfection and sterilization processes. Danger of contagion was reported as dreadful by some or as indifferent by others who thought that it was something that could be controlled and minimized by using standard precautions. HIV and Hepatitis B and $\mathrm{C}$ were the most feared diseases. Based on the discourses, it is possible to emphasize the need to improve the educational strategies, aiming to motivate adherence to Biosecurity guidelines, which are essential when dealing with dental patients.

Keywords: Biosecurity; Dental students; Adherence to guidelines; Qualitative Research.

\section{Introdução}

A biossegurança envolve um conjunto de condutas e medidas técnicas, administrativas e educacionais que devem ser empregadas por profissionais da área de saúde ou afins, para prevenir acidentes e contaminação cruzada em ambientes biotecnológicos, hospitalares e clínicas ambulatoriais (Brasil, 1990, 1995; Gonçalves e col., 1996).

A prevenção da infecção cruzada é aspecto crucial na prática odontológica. Os profissionais que trabalham nessa área devem adotar rotinas básicas de prevenção durante o trabalho (Taiwo e Aderinokun, 2002; Thomas e col., 2008), pois promovem proteção da equipe, pacientes e ambiente de assistência odontológica, minimizando o risco de transmissão de doenças infectocontagiosas (Ferreira , 1995; Gonçalves e col., 1996; Medeiros e col., 1998; Brasil 2000; Garbin e col., 2005).

Entretanto, a literatura sobre Biossegurança e Odontologia tem mostrado, por meio de análise quantitativa - metodologia aplicada à maioria desses estudos - que o grau de obediência do próprio profissional aos protocolos é variável, seja para medidas de proteção individual seja para medidas coletivas (Medeiros e col., 1998; Maupomé e col., 2000; Monarca e col., 2000; Gordon e col., 2001; Maupomé e col., 2002; Taiwo e Aderinokun, 2002; Garbin e col., 2005; Harte e Charlton, 2005; Qudeimat e col., 2006; AlNegrish e col., 2008).

Quando se deseja conhecer os motivos da não adesão a protocolos de biossegurança em saúde, a análise qualitativa é de fundamental importância, verificando pensamentos contidos na consciência humana e entendendo um universo de significados, motivos, aspirações, crenças, valores, atitudes, capazes de interferir com a prática segura (Minayo, 1996; Spink e Medrado, 200o; Lefèvre e Lefèvre, 2003, 2006; Forman e col., 2008). A pesquisa qualitativa tem sido aplicada dentro da área de controle da infecção cruzada (Forman e col., 20o8; Penteado e Lefévre, 2003), proporcionando a oportunidade de os indivíduos se expressarem (Nogueira-Martins e Bógus, 2004). Tem como objetivo compreender e interpretar a experiência pessoal de forma a explicar o fenômeno social, incluindo aqueles relacionados à saúde (Huston, 1998). 
Dentro da Odontologia, os acadêmicos têm sido apontados como o grupo para o qual a educação em Biossegurança e o controle de infecção cruzada são imprescindíveis para correto treinamento e cumprimento dos protocolos rotineiramente. Acredita-se que uma atenção especial às narrativas dos participantes envolvidos no trabalho de cuidado de saúde odontológica irá prover a visão clara sobre como o controle de infecção cruzada, de segurança do paciente e de limpeza são criativamente reconstruídos, bem como as implicações para com o modo como se pensa a dimensão humana do controle de infecção cruzada (Brow e col., 2008). Assim, o objetivo deste estudo foi investigar as percepções de graduandos da Faculdade de Odontologia de Araraquara da Unesp sobre o tema.

\section{Método}

Foi utilizada metodologia de corte qualitativo e optou-se pela técnica do Discurso do Sujeito Coletivo (DSC) (Lefévre e Lefévre, 2003), obtido por meio de análise e processamento das entrevistas realizadas com os acadêmicos. O DSC é a estratégia metodológica qualiquantitativa que permite descrever um conjunto de representações sociais dentro de um imaginário sobre determinado tema de pesquisa (Mazza e Lefèvre, 2004).

A população do estudo consistiu de 14 acadêmicos formandos do curso de graduação da Faculdade de Odontologia de Araraquara da Unesp, do ano de 2007. A exigência de inclusão no estudo foi que esses acadêmicos estivessem realizando atendimento de pacientes em clínicas da faculdade.

Para a coleta de dados foi utilizado o instrumental "entrevista aberta, semiestruturada e individual" (Mazza e Lefèvre, 2004). As entrevistas individuais foram realizadas no ambiente da faculdade, em sala apropriada, garantindo privacidade aos depoimentos. Cuidou-se para que a oportunidade de entrevista fosse facilitada, proporcionando maior entrosamento entre voluntário e pesquisador e se evitasse viés indesejado nas respostas.

No roteiro de entrevistas, oito questões foram abordadas dentro do tema Biossegurança e Odontologia, versando sobre os aspectos de uso e aplicação dos protocolos existentes para nortear a prática clínica, de adesão às medidas de proteção individual e coletiva e sobre medo de contágio.

Os depoimentos foram gravados em gravador de voz digital, após assinatura do Termo de Consentimento Livre e Esclarecido pelos voluntários e o projeto foi aprovado pelo Comitê de Ética em Pesquisa da FOAr-UNESP. Além das entrevistas, a amostra foi caracterizada segundo idade, sexo, vacinação contra hepatite B e realização do teste para verificação da sorologia positiva para o anti-HBsAg, que confere imunidade.

Os dados coletados foram analisados, com o auxílio do programa QUALIQUANTISOFT ${ }^{\circledR}$, em que o processo de interpretação envolveu a atribuição de significado aos depoimentos, dentro de processo criativo envolvendo insights e intuição do pesquisador.

\section{Resultados e Discussão}

\section{Características da amostra}

A média da idade dos entrevistados foi 27 anos, sendo $78,57 \%$ do sexo feminino e $92,85 \%$ vacinados com três doses contra hepatite B. Apenas um aluno (7,15\%) foi vacinado com duas doses. Em relação ao teste para anticorpos HbsAg, 10 alunos $(71,4) \%$ não haviam realizado e, entre os 4 alunos (28,6\%) que fizeram, todos apresentaram imunidade ao teste.

Acredita-se que, embora a etapa de vacinação seja realizada pelos alunos, poucos $(28,6 \%)$ realizaram o teste de imunidade. Embora fosse esperado que houvesse maior interesse e procura pelo teste antiHbsag, principalmente por se tratar de formandos, que já lidam com procedimentos de risco em suas atividades, e em breve estarão no mercado de trabalho, não foi objetivo atual investigar os motivos que determinaram esse comportamento.

Porém, pode-se sugerir que tenha havido pouca informação quanto à necessidade do teste anti-HbsAg. Isso é preocupante, pois se sabe que a eficácia da vacina é de $80 \%$ a $100 \%$ entre os que receberam o esquema completo (Sociedade Brasileira de Pediatria, 2002), e alguns estudantes podem estar expostos a infecções potencialmente letais.

Alguns países, como no Canadá, há faculdades que requerem a prova de imunização dos alunos, no início das atividades com pacientes, garantindo maior segurança ao atendimento odontológico (Luu, 2004). Em outros países, é pouco comum a vacinação 
contra hepatite B (Taiwo e Aderinokun, 2002), ou mesmo a realização de teste de imunidade (Stewardson e col., 2002). No Brasil, entre profissionais da saúde, a vacinação e o teste de imunidade são recomendados. Embora se acredite que a prevenção seja assunto de saúde pública e não de sensibilização individual (Trevisan e col., 2006), as políticas para a vacinação contra hepatite B e a verificação da soroconversão, após 1 a 3 meses do esquema vacinal completo (Sociedade Brasileira de Pediatria, 2002), devem ser mais incentivadas, principalmente com programas educativos nessas comunidades de ensino odontológico.

\section{Ideias-centrais do discurso do sujeito coletivo}

Quanto aos DSC, para cada pergunta foram verificadas as representações sociais sobre o tema Biossegurança e Odontologia. Os resultados qualiquantitativos estão apresentados por questão, com as respectivas Ideias Centrais (IC), no Quadro 1 a seguir.

\section{Quadro I - Quadro-síntese dos DSC e categorias, segundo ideias centrais. Araraquara, 2008}

\begin{tabular}{|c|c|}
\hline Discurso do Sujeito Coletivo das Ideias Centrais (ICs): & $\mathrm{n}$ \\
\hline $\begin{array}{l}\text { Pergunta I-Como você percebe a questão dos protocolos de Biossegurança? } \\
\text { Categoria A: Normas são necessárias e importantes para um trabalho correto } \\
\text { Categoria B: Protocolos devem ser seguidos e ensinados aos alunos para que saibam o que devem fazer } \\
\text { Categoria C: As normas são claras e boas } \\
\text { Categoria D: Os protocolos são teóricos e pouco práticos e por isso não são seguidos de modo ideal } \\
\text { Total }\end{array}$ & $\begin{array}{r}3 \\
2 \\
2 \\
12 \\
19^{*}\end{array}$ \\
\hline $\begin{array}{l}\text { Pergunta } 2 \text { - Fale-me um pouco sobre as medidas que você utiliza contra a contaminação cruzada. } \\
\text { Categoria A: Uso de Equipamento de Proteção Individual } \\
\text { Categoria B: Utilizo as barreiras protetoras } \\
\text { Categoria C: Faço desinfecção e esterilização } \\
\text { Categoria D: Sigo os cuidados com a lavagem das mãos e onde coloco a mão com luvas contaminadas } \\
\text { Categoria E: Realizo a anti-sepsia da cavidade bucal do paciente com bochecho } \\
\text { Categoria F: Não respondeu } \\
\text { Total }\end{array}$ & $\begin{array}{l}8 \\
12 \\
13 \\
3 \\
1 \\
1 \\
38^{*}\end{array}$ \\
\hline $\begin{array}{l}\text { Pergunta } 3 \text { - Para você, o que significa se proteger contra a contaminação? } \\
\text { Categoria A: Obter maior qualidade de vida, visando minha proteção própria, usando EPIs } \\
\text { Categoria B: Evitar a infecção cruzada } \\
\text { Categoria C: Evitar acidentes pérfuro-cortantes } \\
\text { Total }\end{array}$ & $\begin{array}{c}13 \\
8 \\
3 \\
24^{*}\end{array}$ \\
\hline $\begin{array}{l}\text { Pergunta } 4 \text { - } 0 \text { que você considera como fonte perigosa de contaminação, ou seja, de onde vem o perigo para a } \\
\text { sua saúde? } \\
\text { Categoria A: De doenças do paciente } \\
\text { Categoria B: De instrumentos e mãos contaminados } \\
\text { Categoria C: Da matéria orgânica do paciente (sangue, saliva, e aerossol) } \\
\text { Categoria D: Do ambiente do consultório } \\
\text { Categoria E: Da quebra da cadeia asséptica } \\
\text { Categoria F: Do contato com o paciente sem usar máscara ou óculos de proteção } \\
\text { Categoria G: Do uso coletivo da caixinha de revelar radiografias } \\
\text { Total }\end{array}$ & $\begin{array}{c}5 \\
8 \\
10 \\
3 \\
1 \\
3 \\
1 \\
31^{*}\end{array}$ \\
\hline $\begin{array}{l}\text { Pergunta } 5 \text { - E para a saúde de seus pacientes, onde é que está o perigo? } \\
\text { Categoria A: O perigo está na falta de cuidados por parte do profissional ou sua equipe, quando ocorre contaminação } \\
\text { cruzada, ou quando há reutilização de material descartável, ou por instrumental contaminado ou pela roupa } \\
\text { contaminada. }\end{array}$ & 20 \\
\hline $\begin{array}{l}\text { Categoria B: O perigo vem de doenças do próprio profissional, que pode passar para os pacientes. } \\
\text { Total }\end{array}$ & $\begin{array}{c}6 \\
26^{*}\end{array}$ \\
\hline
\end{tabular}


Quadro I- Quadro-síntese dos DSC e categorias, segundo ideias centrais. Araraquara, 2008 (continuação)

\begin{tabular}{|c|c|}
\hline Discurso do Sujeito Coletivo das Ideias Centrais (ICs): & $\mathrm{n}$ \\
\hline \multicolumn{2}{|l|}{$\begin{array}{l}\text { Pergunta } 6 \text { - Você vê diferença nos cuidados quanto à Biossegurança, a serem tomados, para atender alguém } \\
\text { que é sabidamente infectado? }\end{array}$} \\
\hline Categoria A: Não vê diferença; os cuidados devem ser os mesmos & 6 \\
\hline Categoria B: Há diferença, pois toma mais cuidado por medo & 8 \\
\hline Total & $14^{*}$ \\
\hline \multicolumn{2}{|l|}{ Pergunta 7 - Se você se contaminasse ou contagiasse durante as atividades clínicas, qual seria sua reação? } \\
\hline Categoria A: Desesperava ou ficava nervoso & 9 \\
\hline Categoria B: Falaria para o professor ou responsável clínico da faculdade & 4 \\
\hline Categoria C: Aumentaria a forma de se proteger & 1 \\
\hline Categoria D: Manteria a calma, e tomaria as medidas necessárias que são padrão para acidentes pérfuro-cortantes & 9 \\
\hline Categoria E: Tomaria o coquetel mesmo se a chance de contaminação fosse baixa & 1 \\
\hline Total & $24^{*}$ \\
\hline \multicolumn{2}{|l|}{ Pergunta 8 - Você tem medo de se contaminar com alguma infecção especial? Fale-me sobre isso. } \\
\hline Categoria A: Da aids e da hepatite & 12 \\
\hline Categoria B: Não tenho medo & 1 \\
\hline Categoria C: De todas as doenças & 1 \\
\hline Total & $14^{*}$ \\
\hline
\end{tabular}

* 0 total corresponde ao número de sujeitos participantes da composição de cada DSC, podendo ter contribuído com mais de uma ideia central.

\section{Representações sociais}

Embora a apresentação dos resultados pudesse ser feita de modo a ilustrar apenas o DSC da IC mais frequente, ou seja, a mais compartilhada em cada pergunta, optou-se por apresentar os resultados agrupando-se as diferentes IC de cada questão, com o interesse de ilustrar o conjunto de crenças e atitudes obtidas nos depoimentos da amostra e facilitar a discussão.

A seguir, os resultados mostram cada pergunta e o DSC composto, com suas respectivas IC. Para a pergunta 1, obteve-se o seguinte discurso:

\section{Pergunta 1 - Como você percebe a questão dos pro- tocolos de Biossegurança?}

É importante ter normas bem detalhadas pra que sejam cumpridas à risca e seja feito o trabalho corretamente $(1,7)$. Os protocolos foram criados para evitar que eu me prejudique, que eu faça tudo direitinho durante $o$ atendimento (7). Devem ser passados pros alunos para que a gente saiba o que fazer e não fique perdido, quando acontecer algum acidente (2). Na faculdade as normas que ensinam são claras e boas $(3,10,11,12)$. Porém, tanto os professores, quanto os funcionários, deveriam estar cientes e também fazer o uso, da mesma forma que os alunos são cobrados pra fazer isso. Às vezes, os funcionários e professores fazem de modo diferente do que é preconizado (12) e acho que os protocolos são muito rígidos, minuciosos, embora devam realmente ser, para que sejam seguidos passo a passo, até mesmo para que a gente se policie, se discipline pra fazer daquela forma, e depois, com o tempo, vá fazendo naturalmente. Muitas vezes se torna confuso, tendo muitas normas que eu me perco $(5,6,8,9,14)$. Não só entre alunos, mas até mesmo entre professores em clínicas particulares, em consultórios, em serviços públicos, os protocolos não são aplicados corretamente e, embora cursos sejam feitos para se saber melhor quais as etapas que devem ser feitas, muitas etapas são certamente puladas $(8,13)$. A gente acaba pondo a mão contaminada onde não deve (11). Na prática, não se aplica tudo daquele jeito que a gente aprende na teoria $(6,8,9,14)$. É difícil seguir o que as normas dizem, pois sempre uma coisinha ou outra acaba ficando infectada, e a gente não consegue controlar totalmente. No dia-a-dia, ou na faculdade, eu não consigo seguir, nem fazer tudo certinho, porque eu tenho que ser rápido para atender. Isso gasta tempo (10). No consultório individual, tudo bem, pois 
é pra mim que vou viver daquilo (10). Na faculdade eu tento, mas tem horas que não dá e não tem jeito (10), é teórico demais. Aqui na faculdade eu não vi uma biossegurança ideal em nenhum lugar, e olha que eu estou no último ano e não consegui encontrar em nenhum lugar (6). Mas, eu acho que se a gente conseguisse seguir e realmente praticar, aí sim a gente praticaria a biossegurança em si (8).

Os protocolos foram considerados difíceis de serem seguidos, o que concorda com estudo realizado na área médica (Gurses e col., 2008), que aponta fatores relacionados à não colaboração: desconhecimento, não familiaridade ou discordância com as regras denominadas enfadonhas, alta carga de trabalho, falha na adaptação às novas práticas e falta de equipamentos ou recursos necessários (Gurses e col., 2008). Os achados do estudo atual concordam também com a crença de que a obediência aos protocolos consome tempo e recursos (Crossley, 2004a; Crossley, 2004b; Gurses e col., 2008), não sendo facilmente aplicada à rotina de trabalho. Essa crença é motivada pela percepção de que bom profissional é aquele que atende rápido, gerando resultado em procedimento odontológico, deixando para segundo plano o momento de executar uma correta biossegurança.

Esse comportamento pode ser compreendido à luz da teoria de Bourdieu (1990), em que o hábito é uma realidade consubstanciada que frequentemente é tomada por certa dentro de determinado grupo social (Brown e col., 2008). O hábito envolve cultura, imaginário, e meios, historicamente predispostos, de se compreender o mundo, bem como padrões de ação e conduta. A trajetória biográfica e histórica de um indivíduo irá predispô-lo a formas específicas de perceber, conceber, raciocinar e se comportar, o que acaba por lapidar gostos, desejos e sistemas de oralidade, de modo que escapa da atenção consciente (Brown e col., 2008). 0 trecho que fala "acaba pondo a mão contaminada, sem querer” é um exemplo disso. Nesse caso, pode-se dizer que a vida envolve muitos rituais e decisões sobre o termo "sujeira", sendo um assunto que ultrapassa a geografia ou as fronteiras especiais e pode formar o discernimento dentro de um estabelecimento de saúde (Brown e col., 2008).

Essa questão mostrou que, para os alunos, as medidas de prevenção padrão são importantes e claras, porém são muito teóricas e se afastam da rotina prática diária e isso seria um dos motivos para a quebra na fidelidade às diretrizes. Outro motivo seria a necessidade de maiores exemplos pessoais, para se fazer o que é certo em Biossegurança, independentemente do exemplo vir de funcionário, aluno ou docente.

Os participantes ressaltaram a necessidade de estas medidas serem ensinadas "para que os alunos saibam o que fazer". Esse relato é interessante, pois embora haja conteúdo ministrado em aulas teóricas e práticas durante a graduação, os alunos sentem haver distanciamento entre conhecimento aprendido e prática clínica.

A seguir, a pergunta 2 ilustra o DSC sobre os itens de proteção individual e/ ou coletiva utilizados pelos acadêmicos:

\section{Pergunta 2 - Fale-me um pouco sobre as medidas que você utiliza contra a contaminação cruzada.}

Eu uso os EPIs para atender o paciente, com o kit básico, luva, máscara, gorro, jaleco, óculos $(1,5,7,8$, 11, 12, 13, 14). Utilizo as barreiras mecânicas, como sacolés nas hastes dos refletores e troco de paciente pra paciente (1). Coloco plástico nos braços, cabeçote e encosto da cadeira odontológica, protejo com sacolé a seringa tríplice, protejo bancada e mesa clínica com campo (1). Uso sobreluvas, tanto pra pegar resina, ou vidros de materiais, para que não sejam contaminados ao serem pegos por várias pessoas $(2,3,4,8,10,11,12,13,14)$. Além disso, uso campo de proteção pro peito do paciente (5) e tudo que tem que ser descartável (7). Não reutilizo material e sempre uso material estéril (2). Outra preocupação é com a desinfecção do equipo com álcool $70(4,5)$ e com a limpeza e desinfecção dos instrumentais antes de uma esterilização $(7,8,11,12,13,14)$. Faço bochecho para o controle e adequação do meio bucal do paciente, para ele já ter todas as condições de ser submetido a um tratamento sem nenhum risco de contaminação $(1,3,6)$. Faço a lavagem das mãos (14) e evito ficar colocando as mãos com a luva em outros lugares que não seja aqueles que você já fez a proteção [...] (3, 14). Também cuido para lavar as mãos antes de calçar as luvas e após o uso também (8). Eu acho que eu me protejo de todas as formas, usando todos os parâmetros possíveis e tento também proteger o meu paciente (9) [...]. Dessa forma, 
acho que estou utilizando os meios pra evitar essa contaminação (9).

Embora não tenha quantificado os equipamentos de proteção utilizados, os acadêmicos disseram realizar medidas de proteção padrão, recomendadas por protocolos existentes. Houve preocupação com uso das barreiras protetoras em pontos críticos do equipamento odontológico, superfícies passíveis de serem tocadas e contaminadas pela mão do dentista. Estudo anterior verificou quantitativamente a adesão às medidas de proteção, relatando falhas no uso de barreiras no equipamento, de óculos de proteção e de campos protetores, indicando o comportamento perigoso das equipes de atendimento odontológico entrevistadas (Monarca e col., 2000). Um dos grandes desafios para dentistas, pesquisadores e imunologistas tem sido sobre como deter as infecções nos consultórios e clínicas, em que a consciência de que nem tudo que reluz pode estar desinfectado ou esterilizado surgiu com o advento da aids (Ferreira, 1995), havendo aumento da tomada de consciência sobre as medidas de precaução padrão.

Em 2003, o Centro para Controle de Prevenção de Doenças (CDC), o maior órgão federal, líder para a prevenção de doenças nos Estados Unidos, atualizou as diretrizes para o controle de infecção em estabelecimentos de saúde odontológica (Kohn e col., 2004). No Brasil, medidas de prevenção e controle contra a infecção cruzada nos serviços odontológicos foram regulamentadas (Brasil, 2006, 2005). Entretanto, a fiscalização da aplicação dessas diretrizes é de responsabilidade dos centros de vigilância sanitária (CVS), órgãos ligados às Secretarias Estaduais, cujo trabalho tem sido mais voltado para orientação do que punição. Cabe ressaltar que esse órgão que enfrenta falta de recursos e de técnicos especializados para essa fiscalização (Ferreira, 1995). 0 compromisso com a correta conduta em controle de infecção cruzada acaba se tornando uma questão de atitude e conscientização pessoal. A precária descontaminação do meio ambiente do consultório é crítica para a ocorrência de transmissão secundária de doenças (Rebmann e col., 2008).

Diferentes forças que promovem a adesão às precauções universais foram investigadas entre estudantes e profissionais da área de enfermagem e identificou-se que a informação sobre práticas se- guras, isoladamente, era insuficiente para a adesão aos protocolos (Lymer e col., 2004).

Quanto ao uso de bochecho anti-séptico, previamente ao atendimento odontológico, método eficaz na prevenção da contaminação das superfícies pelos aerossóis, a literatura mostra que não é hábito entre os dentistas, embora no estudo atual os acadêmicos disseram utilizar e conhecer as vantagens dessa medida, contra a contaminação cruzada.

A seguir, a questão 3 gerou o seguinte discurso:

\section{Pergunta 3 - Para você, o que significa se proteger contra uma contaminação?}

Eu ter mais qualidade de vida e uma saúde garantida para exercer minha profissão em longo prazo (1). Significa proteger a minha integridade física (5), porque se a gente trabalha com isso, tem que se proteger porque senão sua vida já era (12). Tomo todas as medidas cabíveis para que eu não corra nenhum tipo de risco $(5,9)$. Cuido da minha saúde, porque o paciente ali sentado, pode não falar a verdade na anamnese (10). Uso todos os aparatos de segurança pra me proteger e evitar que fluídos do paciente entrem em contato com pele, mucosa do olho [...] ou materiais $(2,3,4,6,8,11,12,13,14)$. Uma outra forma importante seria tomar vacinas (7). 0 mais importante é cuidar da minha saúde, sen ão como é que vou ter condição de cuidar da saúde de outras pessoas? Outra preocupação é evitar a contaminação cruzada $(5,9,10,14)$, pois eu considero todos os pacientes possíveis de serem infectados por alguma coisa (7). Daí eu tomo cuidado no momento de lavar instrumental, no momento de tratar o paciente, pra não perfurar nada $(7,11,13)$.

Essa questão ilustrou a percepção acerca do preservar-se, ou seja, do importante significado da prevenção contra uma contaminação, para a manutenção da integridade física, visando longevidade e preservação do trabalho. Atribuiu-se algum risco ao fato de o paciente nem sempre relatar a verdade sobre sua própria condição de saúde, ou ainda sobre a necessidade de adesão à vacinação.

A questão 4 mostra o DSC sobre o que foi considerado fonte perigosa de contaminação entre os acadêmicos, ao atenderem pacientes:

\section{Pergunta 4 - 0 que você considera como fonte perigosa de contaminação, ou seja, de onde vem o perigo para a sua saúde?}


Como eu trabalho com gente, vem das pessoas (2, $7,8,10,11,12,13)$, de doenças em estado ativo, por exemplo, um paciente está com herpes, então ali representa um problema no ato, no momento do atendimento (1). Outros problemas mais sérios também, como hepatite e HIV+, ou uma tuberculose, são fatores de risco e devo tomar muito cuidado (1, 8). A proteção com máscara é importante porque evita um pouco, já que a gente está numa distância tão pequena com o paciente (11). O problema é que, eu sou meio tranqüilo, eu sou meio despreocupado, até acontecer alguma coisa o comigo e me preocupo mesmo quando tem paciente de risco (5). Mas, eu considero qualquer paciente como paciente de risco, de alto risco, porque eu não sei só pelo olhar da pessoa se ela está contaminada; muitas vezes nem o paciente sabe se é contaminado (8). Outra preocupação é com os instrumentais pérfuro-cortantes contaminados que a gente usa $(7,8,11)$. As fontes perigosas de contaminação são aquelas que mexem com ambiente crítico, que são sangue (6). Um material odontológico que tem uma matéria orgânica impregnada, contendo vírus HIV, hepatite, a bactéria da tuberculose, o Micobacterium tuberculosis, pode ser fonte de contaminação, caso eu não tenha feito uma desinfecção prévia e colocado direto para a esterilização $(12,13,14)$. Às vezes, a esterilização não consegue penetrar direito, e esse instrumental ainda vai continuar com a contaminação, vai continuar contaminado e numa cirurgia posterior, é possível de eu transmitir doenças pela matéria orgânica acumulada (6). A quebra da cadeia asséptica é um perigo para contaminação (8). 0 contato direto, sem óculos ou EPIs, é o maior perigo (10) pois a boca do paciente é um lugar muito infectado por vários microorganismos (3). Outras possibilidades seriam pela mão contaminada, onde todo mundo põe a mão, e põe na boca do paciente (14), pelos aerossóis que são emitidos, porque contém, não só saliva, sangue, mas tudo coisa que não se vê (4), e pelas roupas do dentista contaminadas pelo aerossol (12). De modo geral, o meio ambiente do consultório é perigoso, é contaminado $(12,13)$, porque não sou só eu quem uso (9). Como eu não sei quem usou o equipamento antes de mim, eu considero então tudo que eu mexo como fonte perigosa de contaminação (9). Um exemplo vivo é a caixinha de revelar radiografias (14).
Relataram as doenças do paciente - cujo veículo seria a matéria orgânica presente no ambiente do consultório, sangue, saliva e aerossol - como perigosa fonte de ameaça ao bem estar físico dos profissionais. Entretanto, pode-se depreender que, embora as diretrizes sejam necessárias para a prevenção da transmissão, é de igual importância a colaboração e a adoção das normas existentes para minimizar o risco de contágio (Harte e Charlton, 2005). Outras fontes seriam a quebra da cadeia asséptica, durante procedimentos clínicos, provenientes da mão ou instrumentos contaminados, do contato com paciente sem a devida paramentação, ou pelo uso coletivo da mesma caixa de revelar radiografias, onde se coloca mão com luva contaminada no conteúdo da caixa, havendo um depósito de microrganismos nessa superfície.

Além disso, verificou-se a percepção de que os acadêmicos podem se expor à contaminação, quando deixam de realizar medidas de Biossegurança na esfera pessoal e coletiva de limpeza, proteção, desinfecção e esterilização, indicando consciência de que o ambiente do consultório é insalubre. A correta noção de que um instrumento sujo não permite adequada desinfecção e limpeza (Tipple e col., 2004) comprova isso.

Durante a prática diária, o dentista está exposto a microrganismos trazidos pelos pacientes. A natureza íntima do meio ambiente entre paciente e dentista, o número de pacientes atendidos, a presença de sangue e saliva, o uso rotineiro de instrumentos afiados e a frequente geração de aerossóis faz do consultório um sítio perigoso para contaminação. Por meio de informação e conscientização em relação aos perigos e, com o uso de proteções individuais e precauções padrão é que a transmissão pode ser evitada (Stewardson e col., 2002). Assim, os estudantes de Odontologia devem estar conscientes do risco existente e devem ser treinados quanto aos procedimentos para efetiva prevenção e ações devidas em caso de exposição ocupacional (Stewardson e col., 2002).

Têm sido realizados alertas diante da necessidade de obediência aos princípios de biossegurança (Thomas e col., 2008; Harte e Charlton, 2005) e estudo anterior verificou que o treinamento frequente aliado à revisão contínua, motivação, trabalho de 
equipe e a compreensão sobre o fundamento em controle de infecção são ingredientes essenciais no alcance e manutenção de altos índices de cooperação (Harte e Charlton, 2005).

Considerando a questão 5 , pode-se observar o seguinte resultado:

\section{Pergunta 5-E para a saúde de seus pacientes, onde é que está o perigo?}

O perigo está na contaminação cruzada $(1,2,5)$, pois eu tenho que prestar atenção para não transmitir bactérias de outros pacientes para eles (2), ou seja, sou eu mesmo o perigo, se eu não tomar cuidado com todas as coisas que tem dentro do consultório (14). As outras pessoas que trabalham comigo representam certo perigo, porque na verdade você não sabe se elas estão fazendo direito ou não. E o pior é que sou eu que respondo por elas. Pode ser perigoso o instrumental odontológico, pela falta de cuidado na hora de lavar, de esterilizar tudo $(6,9,10,12,13)$, ou se eu reutilizar material (2), ou usar material contaminado $(2,3,4,8,11)$. Os ambientes que têm um maior contato com fluidos corpóreos, sangue, saliva também são fonte grande de transmissão. Isso seria a cadeira odontológica, por exemplo, ou a cuspideira, que deve ser sempre desinfectada. A seringa tríplice também, pois é levada da boca de um paciente pro outro, e nem sempre é feita a limpeza adequada. $\mathrm{O}$ instrumental, a mesa clínica, o próprio equipo, onde a gente puxa aquela mesinha do equipo e, muitas vezes, leva contaminação pra ali $(6,9,10)$. Os EPIs e as barreiras protetoras dos equipamentos $(1,7,13,14)$, ou ainda o mesmo jaleco usado a semana inteira, sabe, isso pode ser uma fonte de contaminação (12). Outra possibilidade seria o perigo vir das doenças do próprio profissional, que pode passar pros pacientes (5).

Os acadêmicos percebem sua responsabilidade na prevenção da infecção cruzada e mostram que, embora tenham consciência, possuem comportamentos indesejáveis, como a ausência de proteção ou desinfecção correta dos equipamentos e instrumentais, reutilização de materiais descartáveis e utilização do mesmo jaleco contaminado em diferentes dias da semana. Essa falha de cuidados faz do dentista o principal perigo para o paciente.

A profissão odontológica coloca os estudantes de Odontologia em maior risco de contaminação por infecções hematogênicas provenientes de pacientes. Por isso, se recomenda a imunização contra hepatite B, antes do início das atividades cirúrgicas, seguida da realização do teste anti HbsAg, para verificar soroconversão. Em relação ao risco da transmissão da hepatite ou aids, doenças do profissional para o paciente, embora a probabilidade disso ocorrer seja extremamente reduzida (Shaw, 2008), em certos países há uma preocupação de se testar a efetividade da vacinação contra hepatite $B$, ou mesmo em saber se o aluno é portador, para se preservar a saúde dos pacientes, o que é questionável eticamente (Luu e col., 2004; Shaw, 2008).

Não foi relatada a percepção de contaminação no ar ambiente. Sabe-se que o índice de contaminação microbiana de ar é relevante e especialmente maior durante a atividade de trabalho. Como as medidas de precaução padrão são suficientes para prevenção dos profissionais (Castiglia e col., 2008), provavelmente eles desconhecem o perigo a que estão expostos seus pacientes, principalmente durante procedimentos de preparo dentário com turbinas de alta rotação, sob refrigeração abundante que geram aerossol, que se espalha contaminando não só o ar, mas também o ambiente físico, deixando microrganismos em suspensão. Uma tentativa para minimizar a contaminação do ar, seria a realização de bochechos anti-sépticos, previamente, ou a colocação de isolamento absoluto com dique de borracha, ou ainda a utilização de sucção de alta potência. A inadequada desinfecção no final das atividades de trabalho e a ausência de sistemas de aspiração apropriados propiciam a queda das partículas sobre as superfícies e o nível de contaminação delas não depende exclusivamente do número de pacientes e operadores, mas também da falha do uso de filmes plásticos e papéis de proteção (Castiglia e col., 2008). Por isso, é tão importante proteger as superfícies e usar medidas anti-sépticas na cavidade bucal.

Considerando a questão 6 , surgiram duas categorias diferentes, como ilustram os dois DSC abaixo:

\section{Pergunta 6 - Você vê diferença nos cuidados quanto à Biossegurança, a serem tomados, para atender alguém que é sabidamente infectado?}

6A - Não vejo diferença. Os cuidados têm que ser os mesmos, devo ter o máximo de cuidado independente de saber ou não que o paciente é infectado 
$(1,2,4,6,7,12)$. Devo encarar todos pacientes como sendo fonte primordial de infecção. Todo paciente é contaminado até que prove o contrário, entendeu. [...]. Não dá pra separar um paciente contaminado e aquele fonte não conhecida (6). Entretanto eu percebi que minha colega de trabalho aqui na faculdade, numa específica paciente que a gente sabe que ela tem hepatite B, geralmente se preocupa em usar 2 luvas, usar 2 máscaras. Mas, eu trato de maneira igual porque se a gente usa pra um tem que usar pra todos, porque a gente não sabe sempre.

$6 \mathrm{~B}$ - Não deveria ter diferença, mas tem $(3,5,8,10)$. Eu sinto diferença. Eu acho que me protejo mais, tomo mais cuidado porque fico com um pouco mais de medo, e embora eu use as mesmas formas de proteção com máscara, gorro, luva, fico um pouco receoso $(3,5)$. Quando fico sabendo que aquele paciente é portador de alguma doença infecciosa, atendo nos mais minuciosos detalhes, procuro todas a etapas da biossegurança. 0 que modifica é que fico mais alerta ao manipular o material, justamente para não contaminar (8). Na faculdade, eu passei por este momento de atender o paciente que, só porque o paciente disse que ele era HIV positivo, tudo foi tomado como diferente, embora eu devesse tratá-lo como qualquer doente em potencial. Eu pus aviso no equipo, no instrumental, pois o professor fez eu por "paciente HIV atendido". Mas por quê? E os outros? Isso eu até achei errado. Só porque os outros pacientes não me contaram nada, não significa que eles não eram infectados! E de certa forma eu discriminei o meu paciente, porque quando eu pus o aviso, o paciente ainda estava dentro da clínica, e o professor falou: "pode por o aviso", e eu disse "mas ele ainda não saiu”, “é, mas pode por”. Como a gente ia fechar a clínica, eu pus aviso e o paciente ainda lá. Pra mim foi extremamente constrangedor $(9,13)$. Quando a gente sabe, que está infectado, atende com um certo temor, e os cuidados são maiores; aquelas falhas que a gente, às vezes, deixa passar, não ocorrem ao atender um paciente que é declaradamente infectado $(11,14)$.

O estudo atual concorda com anteriores (Maupomé e col., 2000, 2002; King e Muzzin, 2005) sobre diferenças nessa percepção. Maupomé e colaboradores (2000, 2002) consideraram o atendimento prestado a pacientes com aids, e duas reações foram observadas, tanto medo de prestarem atendimento, por temor de se exporem ou de expor a própria família em caso de infecção, quanto houve a visão de que um paciente portador deveria ser atendido da mesma forma, de que seria uma obrigação moral e profissional. Outros estudos (Crossley, 2004a; Crossley, 2004b; King e Muzzin, 2005) relataram que, embora se fizesse um apropriado uso das medidas de proteção, muitos entrevistados sentiam necessidade de proteção adicional ao atender paciente portador de aids ou hepatite. A emoção por trás desse comportamento é o medo do desconhecido, o pavor de se infectar por patógenos do paciente e a ansiedade adicional ao atendê-lo, mesmo a Odontologia tendo evoluído quanto às medidas de controle de infecção.

Quanto à percepção dos acadêmicos, ao se tornarem alvo de um contágio com alguma moléstia infecciosa durante a prática clínica, a questão 7 ilustra o pensamento coletivo:

\section{Pergunta 7 - Se você se contaminasse ou conta- giasse durante as atividades clínicas, qual seria sua reação?}

Ah eu ia ficar assustado, preocupado e ia procurar o atendimento que aqui na faculdade existe para acidentes pérfuro-cortantes (7). Eu falaria com o professor responsável $(1,3)$, ou procuraria a comissão de Biossegurança para fazer um controle com medicamentos (4) e talvez eu fosse tentar me proteger mais (5). Tentaria primeiramente colocar o paciente informado, não o apavorando pra esclarecer o que aconteceu e procuraria não entrar em pânico, porque somos uma classe de profissionais de risco, e é claro que se eu obedecer as normas de biossegurança terei um risco bem menor (8). Daí, a primeira coisa que faria seria lavar a mão com sabão (12) e seguiria o Protocolo de Biossegurança (1), onde eu entrevistaria o paciente, perguntaria para ver se ele era um de risco ou não (6). Aí eu e o paciente iríamos pro hospital ou pronto-socorro fazer exames e o acompanhamento $(2,8,10,12)$. Dependendo do risco, tomaria a medicação correta (2), mas não sei direito como que é (3) e, se eu percebesse que ele tinha algum risco, eu tomaria o coquetel, mesmo se não fosse necessário (6).

A iniciativa dos alunos seria a procura por socorro, frente a um possível acidente pérfuro-cortante e a 
existência de conhecimento ao seguir tal protocolo. Entretanto, por medo de se infectar, supõem que, mesmo quando o coquetel não está indicado, teriam vontade de tomá-lo. Percebe-se que a realidade sobre a ocorrência de contágio eventual ainda é distante do pensamento coletivo desses alunos.

Em relação ao medo de contágio, a pergunta 8, a seguir, ilustra quais as doenças mais temidas pelos alunos.

\section{Pergunta 8 - Você tem medo de se contaminar com alguma infecção especial? Fale-me sobre isso.}

Sim, tenho medo, acho que tenho medo de todas as doenças (3). Um pouquinho a gente sempre tem (8). A gente lê, ouve falar, mas medo a gente sempre tem, principalmente da aids, que é um mito, apesar de ser muito menos contagiosa que a hepatite. Obviamente, por mais que tenha tratamento para aids, os coquetéis, onde as pessoas atendidas pelos postos de saúde têm uma vida aparentemente mais saudável do que antes, é uma doença muito perigosa (8). Acho que o medo do cirurgião-dentista é da aids e da hepatite $(5,6,7,11,14)$. A hepatite $C$, que pelo que sei não tem ainda tratamento adequado $(1,4,5,7)$. As outras doenças a gente até tolera bem, mas como essas não têm cura, eu tenho medo!!! (6). A hepatite C é perigosa porque pode levar a câncer de fígado, e vírus da hepatite é um vírus mais perigoso até que o da aids (7). Contra a hepatite B eu já sou vacinado, então a preocupação é menor, mas a hepatite $\mathrm{C}$ é a pior (7). A gente sabe que, a via de entrada do HIV no atendimento de restauração ou exame clínico, é pequena, mas ela existe (9). Eu acredito que se tiver cuidado, prevenir e tomar as medidas como uso de gorro, avental, máscara, óculos, faço minha parte (9). Minha profissão nem parece, mas é muito, muito arriscada (9). Eu acho que é fácil você prestar um atendimento médico, o médico te olha, e pode te examinar; na Odontologia, a gente se contagia pondo a mão onde você vai olhar, e aquilo já é uma fonte de contaminação (9). Então a nossa profissão, eu acho que é uma das que requerem maior precaução (9). Tem que ter um certo receio, porque se achar que nunca vai acontecer nada, eu nunca iria me prevenir (10). Eu não atendo paciente pensando "será que eu vou me contaminar", mas eu procuro ser condicionado a ter cuidado; vira uma rotina trabalhar com biossegurança (12). Por outro lado, tem coisas que infelizmente não dá pra manter, e que é bonito na teoria, mas na hora, ali na prática clínica não funciona (13). Mas, também não tenho medo de me contaminar porque eu faço o máximo para me proteger (2).

0 medo dos dentistas ao atender paciente infectado por hepatite ou aids está de acordo com a literatura (Askarian e col., 2007; King e Muzzin, 2005). O significado de que essas doenças não têm cura e afetam a qualidade de vida da pessoa infectada e geram preconceito em relação ao portador parece interferir com a prática de atendimento. Pesquisas indicam relutância por parte de alguns dentistas em atender pacientes infectados, embora sejam eticamente cobrados e responsáveis pelo atendimento sem discriminação (King e Muzzin, 2005; Askarian e col., 2007; Bukar e col., 2008). Outro estudo discute a polêmica questão sobre a restrição da prática profissional por parte de dentistas que se infectam, ou sobre a inibição da formação acadêmica odontológica por alunos portadores (Shaw, 2008), indicando que há necessidade de se ajustar conceitos percebidos e temidos diante da informação científica dos riscos envolvidos na transmissão cruzada em consultório, desmistificando o medo de contágio, pois se sabe que, embora o risco transmissão da aids e das hepatites B e C no atendimento odontológico seja baixo, as consequências podem ser sérias e geralmente estressantes.

\section{Considerações Finais}

Embora a amostra obtida seja de conveniência, o que poderia ser uma limitação, as atitudes e práticas aqui relatadas podem interferir na prática segura. A crença de que embora os protocolos de Biossegurança existam para serem obedecidos, são pouco práticos. Em parte há a responsabilidade e o esforço individual em busca de se cumprir normas; há, porém, a queixa de que nem sempre os exemplos de docentes ou funcionários são adequados. Aparentemente, o fato de os alunos dizerem tomar mais cuidado ao atenderem pacientes sabidamente infectados sugere insegurança nesse atendimento, visto que a obediência aos protocolos não é uma rotina sempre. A insuficiente adesão às normas padrão de Biossegurança em Odontologia representa um 
ponto vulnerável para o contágio ou transmissão de doenças. As atitudes práticas relatadas por alguns entrevistados sugerem falha na compreensão do conceito precauções padrão. Assim, para a adesão correta aos protocolos, o treinamento com ênfase no exemplo e nas atitudes é vital e precisa ser incentivado. A metodologia do DSC permitiu observar crenças e motivos para a quebra dos protocolos padrão e, embora o entrevistado tentasse mostrar conhecimento teórico, falava realmente sobre como percebia o controle de infecção cruzada e as dificuldades existentes no atendimento clínico odontológico, que interferiam com a adesão às diretrizes.

\section{Referências}

ALNEGRISH, A.; AL MOMANI, A. S.; AL

SHARAFAT, E. Compliance of Jordanian dentists with infection control strategies. International Dental Journal, London, v. 58, n. 5, p. 231-236, 2008.

ASKARIAN, M.; MIRZAEI, K.; COOKSON, B. Knowledge, attitudes and practices of Iranian dentists with regard to HIV-related disease. Infection Control and Hospital Epidemiology, Chicago, v. 28, n. 1, p. 83-87, 2007.

BRASIL. Lei n 8.080 , de 19 de setembro de 1990. Dispõe sobre as condições para a promoção, proteção e recuperação da saúde, a organização e o funcionamento dos serviços correspondentes e dá outras providências. Diário Oficial [da] República Federativa do Brasil, Brasília, DF, 20 set. 1990. Disponível em: <https://www.planalto. gov.br/ccivil_o3/leis/l8o8o.htm>. Acesso em: 8 maio 2007.

BRASIL. Ministério da Saúde. Agência Nacional de Vigilância Sanitária. Serviços odontológicos: prevenção e controle de riscos. Brasília, DF, 2006.

BRASIL. Ministério da Saúde. Lei complementar $n^{0} 791$, de 9 de março de 1995. Estabelece o Código de Saúde no Estado. Diário Oficial do Estado, São Paulo, SP, 10 mar. 1995. Disponível em: <http:// dobuscadireta.imprensaoficial.com.br/default.a spx? DataPublicacao=19950310 \&Caderno=DOEI\&NumeroPagina $=1>$. Acesso em: 8 maio 2007
BRASIL. Ministério da Saúde. Secretaria de Políticas de Saúde. Controle de infecção e prática odontológica em tempos de AIDS: manual de condutas. Brasília, DF, 2000.

BRASIL. Ministério do Trabalho e Emprego. Portaria n 485, de 11 de novembro de 2005. NR 32 - Segurança e Saúde no Trabalho em Serviços de Saúde. Diário Oficial [da] República Federativa do Brasil, Brasília, DF, 16 nov. 2005. Seção 1. p. 1-29. Disponível em: < http://www.mte.gov.br/ legislacao/normas_regulamentadoras/nr_32.pdf $>$. Acesso em: 17 jan. 2007.

BROWN, B. et al. The habitus of hygiene: discourses of cleanliness and infection control in nursing work. Social Science \& Medicine, Oxford, v. 67, n. 7, p. 1047-1055, 2008.

BUKAR, A. et al. Discriminatory attitudes towards patients with HIV/AIDS by dental professionals in Nigeria. Odonto-stomatologie Tropicale, Dakar, v. 31, n. 122, p. 34-40, 2008.

CASTIGLIA, P. et al. Italian multicenter study on infection hazards during dental practice: control of environmental microbial contamination in public surgeries. BMC Public Health, London, v. 29, n. 8, p. 187, 2008.

CROSSLEY, M. L. A qualitative exploration of dental practitioners' knowledge, attitudes and practices towards HIV+ and patients with other 'high risk' groups. British Dental Journal, London, v. 197, n. 1, p. 21-6, 2004 a.

CROSSLEY, M. L. An investigation of dentists' knowledge, attitudes and practices towards HIV+ and patients with other blood-borne viruses in South Cheshire, UK. British Dental Journal, London, v. 196, n. 12, p. 749-754, 2004b.

FERREIRA, R. A. Barrando o invisível. Revista da Associação Paulista de Cirurgiões Dentistas, São Paulo, v. 49, n. 6, p. 417-427, 1995.

FORMAN, J. et al. Qualitative research methods: key features and insights gained from use in infection prevention research. American Journal of Infection Control, St. Louis, v. 36, n. 10, p. 764771, 2008. 
GARBIN, A. J. I. et al. Biosecurity in public and private office. Journal of Applied Oral Science, Bauru, v. 13, n. 2, p. 163-166, 2005.

GONÇALVES, A. C. S.; TRAVASSOS, D. V.; SILVA, M. Biossegurança do exercício da odontologia. RPG: Revista de Pós-Graduação, São Paulo, v. 3, n. 3, p. 242-245, 1996.

GORDON, B. L. et al. Systematic review of adherence to infection control guidelines in dentistry. Journal of Dentistry, Guildford, v. 29, n. 8, p. 509-516, 2001.

GURSES, A. P. et al. System ambiguity and guideline compliance: a qualitative study of how intensive care units follow evidence. Quality \& Safety in Health Care, London, v. 17, n. 5, p. 351359, 2008.

HARTE, J. A.; CHARLTON, D. G. Characteristics of infection control programs in U.S. Air Force dental clinics: a survey. Journal of the American Dental Association, Chicago, v. 136, n. 7, p. 885-892, 2005.

HUSTON, P. Qualitative studies: their role in medical research. Canadian Family Physician, Willowdale, v. 44, p. 2453-2458, 1998.

KING, T. B.; MUZZIN, K. B. A national survey of dental hygienists' infection control attitudes and practices. Journal of Dental Hygiene, Chicago, v. 79, n. 2, p. 1-8, 2005.

KOHN, W. G. et al. Guidelines for infection control in dental health care settings-2003. Journal of the American Dental Association, Chicago, v. 135, n. 1, p. 33-47, 2004.

LEFÈVRE, F.; LEFÈVRE, A. M. C. O discurso do sujeito coletivo: um novo enfoque em pesquisa qualitativa (desdobramentos). Caxias do Sul: EDUCS, 2003.

LEFÈVRE, F.; LEFÈVRE, A. M. C. O sujeito coletivo que fala. Interface: Comunicação, Saúde, Educação, Botucatu, v. 10, n. 20, p. 517-524, 2006.

LUU, N. S. Dental students with Hepatitis B: issues to be considered when defining policies. Journal of Dental Education, Washington, DC, v. 68, n. 3, p. 306-315, 2004.
LYMER, U. B.; RICHT, B.; ISAKSSON, B. Blood exposure: factors promoting health care workers' compliance with guidelines in connection with risk. Journal of Clinical Nursing, Oxford, v. 13, n. 5, p. 547-554, 2004.

MAUPOMÉ, G. et al. Survey on attitudes toward HIV-infected individuals and infection control practices among dentists in Mexico City. American Journal of Infection Control, St. Louis, v. 8, n. 1, p. 21-24, 2000.

MAUPOMÉ, G. et al. Attitudes toward HIV-infected individuals and infection control practices among a group of dentists in Mexico City: a 1999 update of the 1992 survey. American Journal of Infection Control, St. Louis, v. 3o, n. 1, p. 8-14, 2002.

MAZZA, M. M. P. R.; LEFÈVRE, F. A instituição asilar segundo o cuidador familiar do idoso. Saúde e Sociedade, São Paulo, v. 13, n. 3, p. 68-77, 2004.

MEDEIROS, U. V.; CARDOSO, A. S.; FERREIRA, S. M. S. Uso das normas de controle de infecção na prática odontológica. Revista Brasileira de Odontologia, Rio de Janeiro, v. 55, n. 4, p. 209-215, 1998.

MINAYO, M. C. O desafio do conhecimento: pesquisa qualitativa em saúde. São Paulo: Hucitec, 1996.

MONARCA, S. et al. Evaluation of environmental bacterial contamination and procedures to control cross infection in a sample of Italian dental surgeries. Occupational and Environmental Medicine, London, v. 57, n. 11, p. 721-726, 2000.

NOGUEIRA-MARTINS, M. C. F.; BÓGUS, C. M. Consideração sobre a metodologia qualitativa como recurso para o estudo das ações de humanização em saúde. Saúde e Sociedade, São Paulo, v. 13, n. 3, p. 44-57, 2004.

PENTEADO, M. S.; LEFÈVRE, F. Biossegurança para agentes biológicos na prática assistencial: um estudo em hospitais da região de Itabuna - BA. 2003. Tese (Doutorado em Prática de Saúde Pública) - Faculdade de Saúde Pública da Universidade de São Paulo, São Paulo, 2003. 
QUDEIMAT, M. A.; FARRAH, R. Y.; OWAIS, A.

I. Infection control knowledge and practices among dentists and dental nurses at a Jordanian university teaching center. American Journal of Infection Control, St. Louis, v. 34, n. 4, p. 218-222, 2006.

REBMANN, T.; CARRICO, R.; ENGLISH, J. F. Lessons public health professionals learned from past disasters. Public Health Nursing, Boston, v. 25, n. 4, p. 344-352, 2008.

SHAW, D. Dentistry and the ethics of infection. Journal of Medical Ethics, London, v. 34, n. 3, p. 184-187, 2008.

SOCIEDADE BRASILEIRA DE PEDIATRIA. Vacina contra hepatite B. [São Paulo]: Associação Médica Brasileira: Conselho Federal de Medicina, 2002. Disponível em: <http://projetodiretrizes.org.br/ projeto_diretrizes/ 115.pdf >. Acesso em: $12 \mathrm{fev}$. 2009.

SPINK, M. J. P.; MEDRADO, B. Práticas discursivas e produção de sentidos no cotidiano: aproximações teóricas e metodológicas. In: SPINK, M. J. P. (Org.). Produção de sentidos no cotidiano: uma abordagem teórico-metodológica para análise das práticas discursivas. 2. ed. São Paulo: Cortez, 200o. p. 41-61.
STEWARDSON, D. A. et al. Occupational exposures occurring in students in a UK dental school. European Journal of Dental Education, Copenhagen, v. 6, n. 3, p. 104-113, 2002.

TAIWO, J. O.; ADERINOKUN, G. A. Assessing cross infection prevention measures at the Dental Clinic, University College Hospital, Ibadan. African Journal of Medicine and Medical Sciences, Oxford, v. 31, n. 3, p. 213-217, 2002.

THOMAS, M. V.; JARBOE, G.; FRAZER, R. Q. Infection control in the dental office. The Dental Clinics of North America, Philadelphia, Pa, v. 52, n. 3, p. 609-628, 2008.

TIPPLE, A. F. V. et al. Acidente com material biológico entre trabalhadores da área de expurgo em centros de material e esterilização. Acta Scientiarum Health Sciences, Maringá, v. 26, n. 2, p. 271-278, 2004.

TREVISAN, A.; BORELLA-VENTURINI, M.; DI MARCO, L. Compliance with hepatitis B virus vaccine: a matter of force? American Journal of Infection Control, New York, v. 34, n. 7, p. 465-466, 2006. 